Check for updates

The BMJ

Cite this as: BMJ 2020;370:m2994 http://dx.doi.org/10.1136/bmj.m2994 Published: 27 July 2020

\title{
Covid-19: England's obesity strategy will fail without tackling social factors, warn doctors
}

\author{
Elisabeth Mahase
}

Having a BMI of 35 to 40 may increase the risk of death from covid-19 by $40 \%$, while a BMI of over 40 could increase the risk by $90 \%$, says a Public Health England report. ${ }^{1}$

In light of this the government has announced a new obesity strategy for England, which includes a ban on television and online advertisements for food high in fat, sugar, and salt before $9 \mathrm{pm}$, calorie content displayed on restaurant menus for food and alcoholic drinks, and an end to "buy one and get one free" deals on unhealthy food.

NHS weight management services will be expanded to reach more people, and GPs will be encouraged to prescribe exercise and more social activities to help people keep fit as part of the plans. Although the plans have been welcomed by several groups, they have said that the government must stand up to the "real enemy"-the food industry-to avoid the strategy becoming "another wasted opportunity."

In 2018 the proportion of adults in England classified as obese (BMI $\geq 30$ ) was 28\%. ${ }^{2}$ PHE has warned that excess fat may affect inflammatory and immune function, which can diminish people's response to infection and increase vulnerability to severe symptoms of covid-19.

For its report PHE assessed the current literature on covid-19 and weight, although it acknowledged that this was not a systematic review. It found that though the evidence did not indicate that excess weight increased the chance of contracting the virus, "obese people are significantly more likely to become seriously ill and be admitted to intensive care with covid-19 compared to those with a healthy BMI."

The report cited a UK study published in Nature that analysed 17 million primary care records and 10926 deaths related to covid-19. ${ }^{3}$ The data "showed an increasing risk of death with increasing BMI (fully adjusted for age, sex, ethnicity, deprivation and co-morbidities) with hazard ratios of 1.05, 1.40, and 1.92 for people with a BMI between $30-34.9 \mathrm{~kg} / \mathrm{m}^{2}, \geq 35-39.9 \mathrm{~kg} / \mathrm{m}^{2}$ and $\geq 40 \mathrm{~kg} / \mathrm{m}^{2}$ respectively, relative to $\mathrm{BMI}<30 \mathrm{~kg} / \mathrm{m}^{2}$, "it said.

PHE also warned that the risk at BMI 35 was 2.56 times higher among people from black, Asian, and minority ethnic groups than among white Europeans,. At a BMI of 25 there was no such difference.

The report also quoted findings from the Intensive Care National Audit and Research Centre's covid-19 report, which used data from England, Wales, and Northern Ireland. ${ }^{4}$ This showed that $31.4 \%$ and $7.9 \%$ of covid- 19 patients who were critically ill in intensive care units had a BMI $\geq 30$ or $\geq 40$, respectively, compared with $28.9 \%$ and $2.9 \%$ of the general population.

PHE said, "The covid-19 pandemic has brought the health crisis caused by overweight and obesity to the fore. The case for action at scale and over the long term to prevent excess weight and support people living with obesity is strong. Doing more for those groups most affected can help improve health overall and help address some of the inequalities in health."

Christina Marriott, chief executive of the Royal Society for Public Health, welcomed the new strategy, but she advised the prime minister to "keep his eye on the real enemy." She said, "Top of the list for cutting our obesity rates must be a commitment to overhauling the obesity causing environments we live in.

"Simply passing the buck to the individual with another healthy eating campaign will not turn the tide on this silent epidemic ... Unless the government has the courage to stand up to industry where it matters-taxing unhealthy foods and restricting the relentless bombardment of junk food and its advertising - we are concerned that the new plans will be another wasted opportunity."

Andrew Goddard, president of the Royal College of Physicians, said that though the strategy took some "significant strides forward," it did not place enough emphasis on the biological, genetic, and social factors that lead to obesity. "There is a risk that we once again fall into the trap of mainly focusing on individual responsibility. We've been down this path before, and it doesn't work," he said. "We know the key to success in addressing obesity and other health inequalities lies in shared responsibility between individuals and the state."

The chair of the BMA's Board of Science, Parveen Kumar, said, "What we need now is for this strategy to be actioned as quickly as possible, with the promised expansion of NHS services delivered in full, with adequate resources and funding, to ensure that those struggling with their weight can get the support they need and deserve, both now and long after the pandemic is over." 
2 NHS Digital. Statistics on obesity, physical activity and diet, England, 2020. 5 May 2020. https:/digital.nhs.uk/data-and-information/publications/statistical/statistics-on-obesity-physical-activity-and-diet/england-2020/part-3-adult-obesity-copy.

3 Williamson EJ, Walker AJ, Bhaskaran K, etal. OpenSAFELY: factors associated with COVID-19 death in 17 million patients. Nature 2020. doi: 10.1038/541586-020-2521-4. pmid: 32640463

4 Intensive Care National Audit and Research Centre. ICNARC report on COVID-19 in critical care. 24 Jul 2020. https://www.icnarc.org/Our-Audit/Audits/Cmp/Reports.

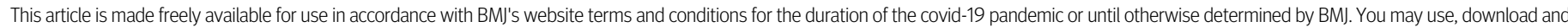
print the article for any lawful, non-commercial purpose (including text and data mining) provided that all copyright notices and trade marks are retained. 